\title{
Presumed consent for organ donation: a clinically unnecessary and corrupting influence in medicine and politics
}

\author{
Author: John Fabre ${ }^{\mathrm{A}}$
}

Presumed consent is a legislative framework in which citizens must place their name on a national opt-out register, otherwise their consent for donating their organs will be presumed. The Welsh Assembly last year passed legislation to enable the introduction of presumed consent in Wales in 2015. The issue is currently being discussed in Northern Ireland, Scotland and the Republic of Ireland. However, there is scant evidence that presumed consent will be effective. Rather than legislating for consent of donors, we should be addressing the misgivings and misunderstandings of families to improve their consent rate, as has been done so successfully in Spain. National improvements in infrastructure in the UK have resulted in an outstanding $63 \%$ increase in deceased donation since 2007. If, now, family consent rates could be improved from the current $57 \%$ to Spanish levels of $85 \%$, the UK's donation rate would be one of the best in the world.

KEYWORDS: Presumed consent, organ donation, transplantation, Organ Donation Taskforce

Presumed consent for organ donation is a powerful tide driven by a curious mixture of good intentions, ignorance and uncritical zeal. The mantra is that presumed consent will quite obviously improve the organ donation rate and save lives. It is a heroic banner for politicians and journalists, and a desperate rallying cry for those who are themselves or whose loved ones are suffering and dying for lack of donor organs.

It is a hugely emotive issue. In 2007, the prime minister Gordon Brown considered presumed consent the foundation for his 'transplant revolution', and the columnist Polly Toynbee in January 2008 regarded the argument for presumed consent as a 'fight with the forces of superstition and reaction. ${ }^{1}$ Recently, Jo-Anne Dobson, a member of the Northern Ireland Assembly, introduced a Private Member's Bill for presumed consent. Her colleagues have described those opposing her as not doing 'the right thing', and the editor of the Belfast Telegraph on 12 February thundered: 'To allow even one person to die through needless delay [in the passage of Jo-Anne Dobson's bill] would be an indelible stain on the Executive's legislative record. ${ }^{2}$

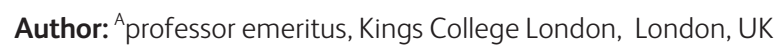

Rational debate, and the formulation of effective policies for improving organ donation, which is what everyone wants, are not easy in these circumstances.

\section{The hugely successful reorganisation of organ} donation in the UK

It is important to step back for a moment and look at what has been happening to organ donation in recent years. Organ donation rates had been falling for almost 20 years, from a peak of approximately 920 donors per annum in 1989-90 - a matter of serious concern for both doctors and patients. However, from a baseline of 809 deceased donors in 2007, it has risen consistently year on year (899 donors in 2008, 959 in 2009, 1,010 in 2010, 1,088 in $2011,1,212$ in 2012) to 1,320 in 2013. This represents a rise of $50 \%$ to 2012 , and $63 \%$ to 2013 , and still rising. ${ }^{3}$ This ongoing and absolutely remarkable achievement has transformed organ donation in the UK, of course without presumed consent.

The credit for this transformation lies with the Department of Health's Organ Donation Taskforce, chaired by Dame Elisabeth Buggins and comprising 15 experts including transplant surgeons, intensive care physicians, nurses and administrators. In January 2008, the Taskforce issued an ambitious report entitled Organs for transplants. ${ }^{4}$ It contained 14 specific recommendations, mainly in the area of transplant coordination (eg the early identification and referral of potential donors) and the retrieval of donor organs. It also made the bold prediction that a $50 \%$ increase in donation was possible over 5 years. To the Department of Health's great credit, the recommendations were implemented throughout the UK, and the predicted increase has been not only achieved, but exceeded.

In 2013, the UK donation rate, ie the number of donors per million of population (pmp), was 20.7.

\section{The country with the world's best donation rate does not use presumed consent}

Spain has consistently had the world's best donation rate, about 32-35 pmp, for more than 10 years, and its family acceptance rate is an outstanding $85 \% .{ }^{5}$ However, Spain does not operate a presumed consent system.

As a result of its pre-eminent international position, advocates of presumed consent very frequently misrepresent Spain, out of either ignorance or wishful thinking. Spain passed presumed consent legislation in 1979. However, the legislation did not have a positive influence on donation, and so, in 1989, crucial organisational 
changes were instituted at a national level. These changes created an organisational infrastructure for transplantation, now internationally known as 'the Spanish system', and it is this system that the UK has emulated so successfully in recent years. It is from 1989 that Spain's donation rate began to rise to the pre-eminent position that it currently occupies.

Many observers have wrongly attributed Spain's success to its 1979 presumed consent legislation. To correct this misconception, the Director of the Spanish Organ Donation Organisation, Dr Rafael Matesanz, was co-author of a paper published in the British Medical Journal (BMJ) in 2010, which clearly stated that the presumed consent law in Spain is dormant. ${ }^{6}$ This paper emphasised that Spain does not have an opt-out register for those who do not wish to become organ donors, and that Spain makes no effort to make its citizens aware of the 1979 legislation. How can there be an operational presumed consent system when citizens have no mechanism to opt out, and when the state does not inform citizens of the existence of the presumed consent law?

If there is any lingering doubt, it is worth noting that in Spain the consent of the donor (even the explicit consent of carrying a donor card) is not sufficient to permit donation to proceed. The written consent of the family is required.

In these circumstances, it is difficult to imagine how anyone can sensibly or honestly persist in the contention that Spain operates a presumed consent system.

It is sometimes argued that the mere presence of the presumed consent legislation in Spain has had a positive cultural influence, even if the legislation has been dormant. It is impossible to argue definitively one way or the other on this point, other than perhaps to note that the positive influence was not seen for the first 10 years after Spain's legislation. In any case, a positive cultural influence of dormant legislation is certainly not what is being contemplated in the UK or what is coming into effect in Wales. Improving cultural attitudes is the key to improving consent rates, but there are less divisive, more effective and, almost certainly, less expensive ways of achieving cultural change than legislating for the consent of donors (see later).

\section{The Department of Health's organ donation taskforce recommended against presumed consent}

Once the Taskforce had completed its report 'Organs for transplants', the Department of Health asked Dame Elisabeth Buggins to examine presumed consent for organ donation. This time there were 21 experts on the Taskforce. There were also additional supporting committees to look at specialist aspects of presumed consent. This report, the most extensive examination ever undertaken of presumed consent, was published in November 2008 and entitled The potential impact of an opt out system for organ donation in the $U K{ }^{8}{ }^{8}$ Its conclusion was clear:

The Taskforce's members came to this review of presumed consent with an open mind, with many sympathetic to the view that presumed consent seems an obvious step forward. However, the more the Taskforce examined the evidence, the less obvious the benefit, and the more multi-faceted and multidimensional the issue of increasing donor numbers was revealed to be. Moreover, there are risks going down the opt-out route which could impact negatively on organ donation. The Taskforce reached a clear consensus in their recommendation that an opt-out system should not be introduced in the UK at the present time.

\section{The popular appeal of presumed consent}

The appeal of presumed consent is based on the notion that there are large numbers of organs out there, and if only we could presume consent these organs could be transplanted and save lives. Many well-meaning people favour presumed consent on the basis that there is an unnecessary wastage of organs caused by people oblivious to the needs of their fellow citizens. It is true that, however much effort is put into donor registers, only around 30 or $35 \%$ of the population join. The remaining $65-70 \%$ either do not like to contemplate their own deaths or are too preoccupied with daily life. The key question is this: will legislating for the consent of these $65-70 \%$ improve the donation rate?

That presumed consent will obviously improve the donation rate is based on two misconceptions: the first is the erroneous idea (espoused in high places, as we shall see) that one must be on the donor register to become an organ donor. If this were true, approximately $70 \%$ of the UK population could not become donors. The truth is that, if a person is not on the donor register, the decision about donation rests with the family. Currently, about $60 \%$ of organ donors in the UK are not on the donor register. $^{3}$

The second misconception concerns the circumstances of donation. With rare exceptions, organ donation is possible only if someone is on a life support system in an intensive care unit (ICU). Otherwise, the organs deteriorate within a few minutes of death and are unusable. A typical circumstance for donation is that someone has cheerfully kissed their family member goodbye in the morning, and in the evening they are unexpectedly in an ICU with their loved one in a coma on a life support system (usually as a consequence of a stroke or a road accident), with doctors and nurses saying that their loved one is dead or dying. This is not a situation in which staff like to make assumptions about the family's wishes about something as sensitive as the removal of organs within a few minutes of death. It is also not a situation in which families are likely to place much weight on the failure of their loved one to have put their name on an opt-out register. Nor is it a situation in which, in practice, the wishes of the family can be ignored. It is a situation in which trust in doctors and the organ donation process is paramount.

\section{Will presumed consent provide additional donors?}

The potential for additional donors is likely to vary with the manner in which the legislation is implemented. If the consent of the family remains a requirement, the situation is little different from the current system, and the legislation is unlikely to make a discernible difference. This was recognised in the discussions leading to the presumed consent legislation in Wales, eg it is noted that 'The closer you are to ordinary (ie current) practice, the less benefit there is in passing the legislation'. ' It is for this reason that families in Wales will not be asked for their consent (see later).

If any additional donors are to come from the presumed consent legislation, it will be from families who are not happy about organ donation, but who lack the social confidence to say so when it is left for them to oppose the system unasked. This is especially so in the daunting and unfamiliar environment of an ICU, and in the context of a sudden and unexpected 
bereavement. This is not a healthy foundation on which to build transplantation.

It is sometimes said that even one additional donor from presumed consent legislation would make it worthwhile. Things are not so simple. The Organ Donation Taskforce estimated in November 2008 that, for the UK, there would be set-up costs of approximately $\mathfrak{£} 45$ million (secure database, public awareness campaign) and approximately $\mathfrak{£} 2$ million per annum running costs. ${ }^{8}$ These costs represent NHS resources that might be spent more productively on other initiatives to improve organ donation, or otherwise improve healthcare in the NHS.

\section{Presumed consent has compromised the integrity of the political process in Wales}

\section{A false statement at the core of the official papers}

Clause 102 of the Explanatory Memorandum to the Human Transplantation (Wales) Bill, published in December 2012, states 'For example, an opt-out system is operated in Spain and it has the highest donation rate in the world'. ${ }^{10}$ This clause appears under the heading 'Evidence base to establish impact of Proposed Legislation'. This false statement, at the core of the official papers underpinning the presumed consent legislation, undermines the integrity of the democratic process. This was pointed out to the responsible ministers, but they simply evaded the issue. There has been no attempt to correct the error, and no apology to the public or to Assembly members who might have been misled. Admitting the error would of course have been an embarrassment for the ministers, and would have undermined the legislation being discussed at the time in the Assembly.

\section{Factually incorrect statements by senior politicians}

In an interview with The Observer in May 2010, the First Minister for Wales, Carwyn Jones, stated 'At the moment, if people are not carrying donor cards then it is presumed that they didn't want to be a donor." As we have seen, this is wrong. Mr Jones's statement implies that the approximately $70 \%$ of the UK population not on the donor register cannot currently become donors. Mr Jones did not mean to mislead, but, as First Minister, he should get things right. His words carry weight.

\section{Misleading statements about the role of the family}

All surveys show that the public regard involvement of the family in the organ donation process as a matter of high importance. Hence the legislation in Wales is always described as 'soft' presumed consent, ie the family will be involved.

The reality is that families will be involved, but not as they expect to be. From 2015, Wales will be the only region in the UK where families will not be asked for their consent to donate their loved one's organs. This has been made clear on several occasions, eg Lesley Griffith, the minister for health at the time, stated that family members 'are not being asked to make a decision on donation, but rather to provide information. This is because the deceased has already made a decision to have their consent deemed.' ${ }^{12}$

Families will be involved in two areas: first, as is currently the case, families 'will still be asked to confirm details of the deceased's health and lifestyle which might not be in the medical records and which could affect their suitability as a donor. ${ }^{13}$ This involves matters such as intravenous drug use. Second, the family 'will be able to say whether they have any information that would lead a reasonable person to conclude that the deceased person would not have consented, ${ }^{14}$ ie families will be asked if they have explicit evidence that their loved one was not in favour of donating organs.

The legislation in Wales cannot honestly be described as 'soft' presumed consent.

\section{Bolstering presumed consent with unreliable statistics}

Throughout the official papers and the political discussions, the Welsh government states that it expects a $25 \%$ increase in donation as a consequence of presumed consent. This prediction is based on 'between-country' comparisons, especially that by Abadie and Gay ${ }^{15}$ specifically mentioned in the Explanatory Memorandum. ${ }^{16}$ The Organ Donation Taskforce was concerned that the conclusions of the betweencountry studies were biased because they excluded from their analyses small countries with presumed consent, but with low transplantation rates, ${ }^{8}$ eg Greece is not included in the analysis of Abadie and Gay. Moreover, they incorrectly assigned Spain as a presumed consent country. There is no reliable basis for the prediction of a $25 \%$ increase in donation in Wales.

Rather than cite old surveys, it is probably more reliable to look at the present: currently, two of the top five donor countries (Spain and the USA) ${ }^{5}$ do not operate presumed consent systems.

\section{Presumed consent will compromise the ethics of clinical practice}

A hitherto uncompromised cornerstone of medical ethics is that consent that is not informed is valueless. Presumed consent is the absence of an objection, and the absence of an objection cannot be taken as informed consent. It has never previously been acceptable in clinical practice. Presumed consent will erode this fundamental principle, for no good reason.

\section{The position of the British Medical Association}

The British Medical Association (BMA) has been a vocal supporter of presumed consent since it was approved by its annual representatives meeting (ARM) in $1999 .{ }^{17}$ This was well before the Department of Health's Organ Donation Taskforce recommended against presumed consent in 2008. The BMA has constantly advocated presumed consent as part of a package, but has never been specific about the components of the package. In the interim (as noted above) the Department of Health's Organ Donation Taskforce recommended in 2008 against presumed consent and in the same year provided a detailed package of recommendations, the implementation of which has been spectacularly successful - a $63 \%$ increase in donation over 6 years, and still rising. ${ }^{3}$ The BMA continues to advocate presumed consent as part of a package. ${ }^{18}$

Motion 303 at the 2011 ARM was that the BMA should reconsider its position on presumed consent. None of the six speakers were involved in transplantation. The approximately 500 representatives, virtually none of whom would be familiar 
with organ donation, voted in favour of the BMA's retaining its support for presumed consent. ${ }^{19}$

The ARM is a democratic forum, well structured to consider issues of general relevance to doctors and healthcare policies. However, it is scarcely credible that the BMA could choose the ARM to make policy on a complex issue requiring informed scrutiny, particularly on the basis of the brief, uninformed and sometimes misleading discussion that took place in 2011.

\section{Consent is now the key issue}

The consent rate in the UK, ie the percentage of approached families who approve donation, was 57\% in 2010, 55\% in 2011 and $57 \%$ in 2012. ${ }^{3}$ By contrast, the consent rate in Spain in 2010, 2011 and 2012 was $81 \%, 84 \%$ and $84 \%$, respectively, ${ }^{5}$ without presumed consent. This difference represents a massive and unacceptable waste of organs in the UK.

The huge increase in donation in the UK over the past 6 years, from 809 donors in 2007 to 1,320 donors in 2013, has been obtained by improving infrastructure, with better identification and referral of donors in ICUs, among other things. The consent rate has remained largely static over this period. If the consent rate in the UK could be increased from $57 \%$ to $84 \%$, this by itself would bring the UK donation rate to about 31 donors pmp - one of the best in the world, and soon challenging Spain for the top slot.

\section{The way forward}

Rather than legislating for the consent of donors, we should be addressing the misgivings and misunderstandings of families so that they decline donation much less frequently, as has been done so successfully in Spain.

An acceptance rate of $85 \%$ is a realistic and achievable objective for the UK over a 5-year period. As previously, we have the Spanish as a model to guide us. It will not be easy. It will require planning, imagination, resources and a detailed plan at the national level, as was done in 2008 by the Organ Donation Taskforce for improving infrastructure. Perhaps Dame Elisabeth Buggins should be asked to chair another Taskforce. And perhaps influential medical organisations should reconsider the support that they gave to presumed consent in the early 2000s, in the light of the 2008 Taskforce reports $^{4,8}$ and the 2010 BMJ paper. ${ }^{6}$ The Royal College of Surgeons of England, noted by the $\mathrm{BMA}^{20}$ and the press ${ }^{21}$ as a supporter of presumed consent in 2008, issued a position statement in 2013 that took a neutral stance. ${ }^{22}$

\section{References}

1 Toynbee P. Living people matter. When you're dead, you're dead. 2008. Available online at www.guardian.co.uk/commentisfree/2008/ jan/15/politics.publicservices [Accessed 23 May 2014].

2 Editor's viewpoint. No time to lose on organ donation. 2014. Available online at http://belfasttelegraph.co.uk/opinion/editorsviewpoint/no-time-to-lose-on-organ-donation-30001340.html [Accessed 23 May 2014].

3 NHS Blood and Transplant. Organ donation statistics. Available online at www.organdonation.nhs.uk/statistics/transplant_activity_ report/ [Accessed 23 May 2014].

4 Department of Health. Organs for transplants. A report from the Organ Donation Taskforce. London: DH, 2008. Available online at http://webarchive.nationalarchives.gov.uk/20120908002807/ http://www.dh.gov.uk/prod_consum_dh/groups/dh_digitalassets/ @dh/@en/documents/digitalasset/dh_082120.pdf [Accessed 23 May 2014].

5 Organizacion Nacional de Trasplantes. International figures on donation and transplantation, 2012. 2013 Newsletter. Available online at www.ont.es/publicaciones/Documents/newsletter_ transplant_vol_18_no_1_september_2013.pdf [Accessed 23 May 2014].

6 Fabre J, Murphy P, Matesanz R. Presumed consent: a distraction in the quest for increasing rates of organ donation. $B M J$ 2010;341:922-4.

7 Organizacion Nacional de Trasplantes. Donor card. Available online at www.ont.es/informacion/Paginas/TarjetadeDonante.aspx [Accessed 23 May 2014].

8 Department of Health. The potential impact of an opt out system for organ donation in the UK. A report from the Organ Donation Taskforce. London: DH, 2008. Available online at www.odt.nhs.uk/ pdf/the-potential-impact-of-an-opt-out-system-for-organdonation-in-the-UK.pdf [Accessed 13 June 2014].

9 Human Transplantation (Wales) Bill. Stage 1 Committee Report. Clause 210. March 2013. Available online at www.assemblywales. org/bus-home/bus-business-fourth-assembly-laid-docs/cr-ld9275e.pdf?langoption $=3 \& \mathrm{ttl}=\mathrm{CR}-\mathrm{LD} 9275 \% 20-\% 20 \mathrm{Health} \% 20 \mathrm{and} \% 20$ Social\%20Care\%20Com [Accessed 23 May 2014].

10 Human Transplantation (Wales) Bill. Explanatory Memorandum. Clause 102. December 2012. Available online at www.assemblywales. org/bus-home/bus-business-fourth-assembly-laid-docs/pri-ld9121em-e.pdf?langoption=3\&ttl=PRI-LD9121-EM\%20-\%20 Human\%20Transplantation\%20\% [Accessed 23 May 2014].

11 McVeigh T. 'Opt-out' organ donation plan offers hope to transplant patients in Wales. May 2010. Available online at www.guardian. co.uk/society/2010/may/09/opt-out-organ-donation-wales [Accessed 23 May 2014].

12 Human Transplantation (Wales) Bill. Stage 1 Committee Report. Clause 253. March 2013. Available online at www.assemblywales. org/bus-home/bus-business-fourth-assembly-laid-docs/cr-ld9275e.pdf?langoption=3\&ttl=CR-LD9275\%20-\%20Health $\% 20$ and $\% 20$ Social\%20Care\%20Com [Accessed 23 May 2014].

13 Human Transplantation (Wales) Bill. Explanatory Memorandum. Clause 42. December 2012. Available online at www.assemblywales. org/bus-home/bus-business-fourth-assembly-laid-docs/pri-ld9121em-e.pdf?langoption=3\&ttl=PRI-LD9121-EM\%20-\%20Human\%20 Transplantation $\% 20 \%$ [Accessed 23 May 2014].

14 Human Transplantation (Wales) Bill. Explanatory Memorandum. Clause 44A. December 2012. Available online at www.assemblywales. org/bus-home/bus-business-fourth-assembly-laid-docs/pri-ld9121em-e.pdf?langoption=3\&ttl=PRI-LD9121-EM\%20-\%20 Human\%20Transplantation\%20\% [Accessed 23 May 2014].

15 Abadie A, Gay S. The impact of presumed consent legislation on cadaveric organ donation: A cross-country study. J Health Econ 2006;25:599-620.

16 Human Transplantation (Wales) Bill. Explanatory Memorandum. Clause 103. December 2012. Available online at www.assemblywales.org/bus-home/bus-business-fourth-assembly-laid-docs/ pri-ld9121-em-e.pdf?langoption=3\&ttl=PRI-LD9121-EM\%20-\%20 Human\%20Transplantation\%20\% [Accessed 23 May 2014].

17 Beecham L. BMA wants presumed consent for organ donors. BMJ 1999;319:141.1.

18 BMA. Rise in donor numbers can be built on. 2013. Available online at http://bma.org.uk/news-views-analysis/news/2013/ april/rise-in-donors-can-be-built-on-says-bma [Accessed 23 May 2014].

19 Triggle N. Organ donor challenge over-ruled at BMA conference. 2011. Available online at www.bbc.co.uk/news/health-13930136 [Accessed 23 May 2014]. 
20 BMA press release archive. BMA briefing paper - presumed consent for organ donation. Available online at http://web2.bma.org.uk/ pressrel.nsf/wall/1A67C9FAF07E171D80257501003CE71D?OpenD ocument [Accessed 13 June 2014].

21 Boseley S. Taskforce opposes 'presumed consent' for organ donors. 18 November 2008. Available online at www.theguardian. com/society/2008/nov/18/organ-donation-health1 [Accessed 13 June 2008].
22 The Royal College of Surgeons. Policy position regarding organ donation. February 2013. Available online at www.rcseng.ac.uk/ policy/documents/organdonationpolicypositionFeb13.pdf [Accessed 23 May 2014].

Address for correspondence: Prof J Fabre, Kings College London, The Strand, London WC2R 2LS, UK.

Email: john.fabre@kcl.ac.uk

\title{
DNACPR decisions: challenging and changing practice in the wake of the Tracey judgment
}

\author{
Authors: Zoë Fritz, ${ }^{\mathrm{A}}$ Nick Cork, ${ }^{\mathrm{B}}$ Alex Dodd ${ }^{\mathrm{C}}$ and Alexandra Malyon ${ }^{\mathrm{D}}$
}

The Court of Appeal judgment that Janet Tracey's human rights had been breached when a 'do not attempt cardiopulmonary resuscitation' (DNACPR) form was written about her without her knowledge has far-reaching implications for clinical practice. The 'duty to consult' extends to all patients apart from those in whom it is likely that discussion would cause 'physical or psychological harm'. The ethical basis for this judgment is strong: if a patient is unaware that a resuscitation decision has been made, he or she cannot ask questions, plan the future or ask for second opinions. Clinicians have, however, expressed concerns about the logistic implications of this judgment in terms of time and resource allocation, and the possibility that doctors will refrain from making resuscitation decisions at all, rather than risk uncomfortable discussions or litigation. Problems with DNACPR decisions predate the Tracey case, and a coordinated alternative approach is needed: patients should be given information so that they can anticipate, initiate and participate in discussions; resuscitation decisions should be considered early in treatment, in a community setting or at predictable junctures; resuscitation should not be considered in isolation but within the context of other goals of care. Models addressing these issues have been developed.

KEYWORDS: Tracey judgment, DNACPR, cardiopulmonary resuscitation, resuscitation orders, medical ethics and law, European Convention on Human Rights

Authors: ${ }^{A}$ wellcome fellow in bioethics, Warwick University, Warwick, UK and consultant in acute medicine, Cambridge University Hospitals NHS Foundation Trust, Cambridge, UK; ${ }^{B}$ medical student, University of Cambridge School of Clinical Medicine, Cambridge, UK; ' medical student, University of Cambridge School of Clinical Medicine, Cambridge, UK; ${ }^{\text {nurse }}$ researcher, Department of Acute Medicine, Cambridge University Hospitals NHS Foundation Trust, Cambridge, UK.
The judgment in $R$ (on the application of Tracey) $v$ Cambridge University Hospital NHS Trust is highly significant. The Court of Appeal judged that considering a decision about a patient's cardiopulmonary resuscitation (CPR) status engages Article 8 of the European Convention of Human Rights, and that this right may be breached by a failure to involve the patient in the process leading to completion of a do not attempt cardiopulmonary resuscitation (DNACPR) form. This judgment has placed a requirement on clinicians to 'consult' with patients, except in very limited circumstances, when a DNACPR decision is considered.

While her case will be familiar to many, it is worth summarising Mrs Tracey's clinical details before looking at some of the broader questions which arise from the judgment. Janet Tracey was admitted to Addenbrooke's Hospital on 19 February 2011, after a road accident in which she sustained a serious cervical fracture. She had metastatic lung cancer and chronic lung disease with an estimated prognosis of 9 months. She was intubated and ventilated, and had two failed extubations. The family were informed that, if the third extubation failed, Mrs Tracey would be 'allowed to slip away', but there was no documentation of a discussion with Mrs Tracey.

A DNACPR form was written, and Mrs Tracey was successfully extubated and moved to the ward. The family subsequently discovered the DNACPR form and asked that it be removed, which was done. Unfortunately, Mrs Tracey deteriorated further and, after discussions with the family (Mrs Tracey was clear at this point that she did not want to discuss resuscitation herself), a second DNACPR form was completed: Mrs Tracey died on 7 March 2011 without attempted CPR.

Mrs Tracey's family brought a case against Cambridge University Hospitals NHS Foundation Trust and the secretary of state for health. Judicial review was undertaken by the Court of Appeal on 6 and 7 May 2014 as to whether the Trust had been in breach of Mrs Tracey's human rights by not informing her of a DNACPR form that had been written while she was in intensive care, and by not having 